\section{MEDICAL EDUCATION IN GREAT BRITAIN}

$\mathrm{T}$ HE report of the Inter-Departmental Committee on Medical Schools, of which Sir William Goodenough is chairman, is summarized on p. 322 of this issue. The report itself must be read if the Committee's recommendations are to be fully understood. Some of them involve considerable changes in outlook and teaching in both the schools and universities of Britain; others profoundly concern the general public ; yet others will hearten the reader and lead his thought beyond the technical details of medical education. For medical work must always be closely bound up with the structure and work of society, and the medical practitioner has to play an important part in social evolution. Any serious consideration of his training must therefore be just what this report is-a sociological as well as a medical document. Several of the reforms which it proposes are similar to, if not identical with, the reforms recently suggested by the Planning Committee of the Royal College of Physicians (which were summarized in the Lancet, 607 ; May 6, 1944, and the British Medical Journal, 668 ; May 13, 1944), so that the views of these two committees can be considered together. In both, the inevitable interaction between scientific method and the older ideal of the art of medicine is evident, and both reports seek to preserve the best elements of the two methods of approach to the patient. Both emphasize the future need to ensure the maintenance of health rather than to await the onset of disease.

The recommendations of the Goodenough Report have the support of "the vast majority of those who are responsible for and engaged in medical education and research in all parts of Great Britain". They must therefore carry great weight. This report points out that, while some of its recommendations could be introduced during this War, others need time to mature. Even if this were not true, doctors cannot be quickly produced, and both the reports under consideration should be read by those who are confronted with the very urgent need for large numbers of doctors in India (see Nature, 658; May 27), and elsewhere. In the U.S.S.R., where the need has been, and still is, urgent, a system based on the idea of industrial 'shifts' has been utilized. It is good to know that the Goodenough Committee, which is able to plan for a country in which the need is less insistent, prefers quality to rapid production. Wide publicity should be given to its firm statement that medical schools should regard themselves as under a definite obligation to do all in their power to meet the need for more doctors, but that they should not take in more students than they can train properly. This Com. mittee urges that, in order to shorten the time lag between the initiation of the reforms which it proposes and the production of their results, action should be taken as soon as possible to create postgraduate courses for practitioners, to build up an adequate supply of teachers, and to assist medical schools by means of financial grants, priority of building materials and labour, and so on, and by provision of adequate staffs, accommodation and equipment. But the Committee also urges that all its recommendations should be initiated as soon as possible, because the success of many schemes of non-medical post-war development will depend upon an adequate supply of doctors who have the right training and outlook. Greatly increased financial support from public funds will be required if we are to secure a sound foundation for national health. The total capital expenditure that should be incurred may amount, within ten years, to ten million pounds at pre-war costs, and recurrent grants will have to be increased until they total, after ten years, three or four million pounds a year at pre-war values. These increases in recurrent grants would thus represent, after ten years, only 2 per cent of the estimated cost, in the first year, of the national health service. It will be agreed that this is a "reasonable price for the community to pay for a service which is vital to the promotion of national health".

As the Goodenough Report says, "Properly planned and carefully conducted medical education is the essential foundation of a comprehensive health service". The Committee thinks it advisable to stress this point, because current discussions of a health service show signs of premature concentration on the detailed structure of such a service and neglect of its essential foundation, and because problems of medical education and research are not the exclusive concern of the medical schools and the medical profession. The general public should maintain a lively and understanding interest in them. The doctor of the future will, the report suggests, become the adviser on the health of both the individual and the community, and will have the responsibility of ensuring one of the principal aims to which national policy is being directed, namely, the achievement by everyone of the highest possible standard of physical and mental health. This is but a modern statement of that spirit of service which has been at all times the distinguishing mark of the medical man.

While the nation can, the Goodenough Committee thinks, rightly be proud of British medical practice and education as it is, the doctor has not been adequately trained in the past to shoulder his new responsibilities for national health. He has studied disease itself more than the promotion of healthand disease chiefly as it is seen in individuals. $\mathrm{He}$ has been taught, as the British Medical Journal (648; November 20, 1943) pointed out, too much about how people die and too little about how they live. One of the basic proposals of the Goodenough Committee is that emphasis must be placed throughout the whole of undergraduate and postgraduate medical training on a sound knowledge of how to produce and maintain a healthy nation. This is made clear in the section of the report devoted to social medicine. A new orientation of medical education is required to give effect to this general idea. It involves a big expansion of the social work of hospitals and radical changes in the outlook and methods of most of the teachers. The developments discussed in this 
section on social medicine will interest the layman profoundly.

The layman will be no less interested in the chapters of the report devoted to child health, maternity and psychiatry. Better provision for the welfare of children and their mothers will have to extend beyond the sphere of medicine; but doctors will have to play a leading part in them. In general, the teaching about children and their mothers has not been adequate, and proposals are made to remedy this deficiency. If, moreover, the doctor is to grasp modern conceptions of disease or to treat some illnesses properly, he must have better instruction in the normal and abnormal working of the human mind. Every medical school ought therefore to have a department of psychiatry, the work of which should be related to that of other departments. The supply of teachers for these departments also is inadequate, and their training is an urgent need.

In their discussions of all these matters the two reports under consideration agree in main principles. Both also express similar views on the necessity of teaching principle and. method rather than fact, especially during the early training of the medical student, on the requirement that at least a year should be spent in a resident hospital post, on the need for drastic reorganization of the medical curriculum with a concomitant reform of the examinations held, on revision of methods of selecting medical students and on the need for adequate training and remuneration of the teachers of medicine and for the betterment of the position of the clinical teacher.

The Committee of the Royal College of Physicians proposes that all university fees should be abolisheda proposal which is not so revolutionary as it sounds when we remember that, as the British Medical Journal has reminded us (665, May 13), the present fees paid cover only about one third of the cost of the education given. The Goodenough Committee does not go so far as this. It is not, indeed, within its terms of reference to consider university fees in general. But it makes proposals for the financial maintenance of the medical student throughout his whole training and others for the supervision of his health, housing and recreations which go much further than mere remission of fees. If they are adopted, no parent, however meagre his means, need hesitate to launch his son or daurghter upon the varied adventures in public and private service which medicine makes possible; nor need he worry about his child's health or future opportunities. The daughter, moreover, would no longer have to run the risk of exclusion by the medical schools. Co-education of men and women would be universal and Exchequer grants could be withheld if reasonable numbers of women were not admitted.

This question of the selection of the prospective medical student would seem, indeed, to be the keystone of the recommendations of both these committees. For both insist that the right kind of student must be obtained at the very beginning and that all classes of society must be enabled to provide candidates for medicine. Both committees further insist that the medical student's character and per- sonality must be adequately considered when he is being selected. Both dislike selection by examination alone, because this favours undesirable specialization at school and thus may prejudice that broad school education which the doctor especially requires.

Whatever the decision may be about the necessity or otherwise of a selecting examination, it is clear that the task of interviewing every candidate for admission to our medical schools would be a formidable one. It would not be easy to make sure that the interviewers created and maintained in the future a uniform standard of selection all over the country. They would have to interview, the British Medical Journal (655; May 13) states, some 2,500-5,000 prospective students every year; and, if the number of doctors is going to increase considerably, as the Goodenough Committee suggests that it will, this task of interviewing would increase in proportion. Nor will everyone feel disposed to give the school record too large a share in the selection of our future medical men. The real characters and abilities of boys and girls are not always discernible at school; they can also be easily misunderstood by some inter. viewers who may have nothing to guide them but what they can learn at a single interview, together with a school record of doubtful value and perhaps the opinions of a school teacher who, however able he may be, must often, especially in large schools, imper. fectly understand some of his pupils. Both school teacher and interviewer might easily fail to discern abilities which, even if they did not fit a pupil to become a good medical practitioner, might help him to do good work in other fields of medicine.

The humble potential patient in all of us may be even more doubtful of tests of intelligence or aptitude which might, it is suggested, help in the selection. It will not be surprising, indeed, if many readers of these reports reject all the arguments which would seek to reduce the importance and efficiency of that popular scapegoat, the examiner. They may not wish to adopt the desperate remedy once proposed by no less an authority on the human mind than William McDougall, namely, examinations for the selection of examiners; but they may suggest that examinations can be altered and that it should not be an insuperable task so to modify the university entrance examination-which is the standard of entry to medicine required by the Goodenough Report-that it would at any rate help to select the qualities required in the medical student. It might even turn out that the main faults of the examination system lie not in the system itself, but in the type of questions asked and especially in the practice of allocating marks by number. If the selecting examination included an oral examination, which should, so many experienced examiners think, be a feature of all examinations, because it gives the candidate a golden opportunity to reveal just those qualities which cannot be expressed on paper or in a practical test, this could be made the occasion of the interview desired by these two reports.

Taking it by and large, the layman who is to be treated when he is ill by the future doctor may prefer that the character and personality of the medical 
student should not be accorded too high a value when he is being selected at the outset of his career by individuals who may never, even if they happen to be specially qualified psychologists, assess them correctly. In any event, these qualities will develop during a course of training which should, if it is properly designed, eliminate the misfits and direct them to more suitable work. The Goodenough Com. mittee, in fact, specifically proposes that there should be means of eliminating such misfits as early as possible in their undergraduate careers. Selection can, in other words, be imposed too early, and the value of the natural selection of the medical school and the hospital can be under-estimated. This is especially true of the medical student, who cannot possibly know, until he begins to handle patients, whether he either wishes to be, or is fitted to become, a practising doctor. It would therefore seem to be wiser to emphasize selection at a later stage of his career, when he has tasted clinical work. Little would be lost by this if the Goodenough Committee's excellent provisions for the direction of each student into the sphere of work for which he proves to be best fitted are adopted. This would amount, in effect, to the selection by each student of his own career. It seems a pity that all university students cannot be given, by means, for example, of a first year during which they could taste, under the guidance of a tutor, every field of university work, a similar chance to select, under supervision, the work which offers them the best chances of combining in their lives a natural inspiration and interest and service of practical value to themselves and to the community. For the value to medicine of the nonmedical worker is well recognized. The Goodenough Committee would, in fact, make special provision for the assistance of workers in other fields who may wish to switch over to the study and practice of medicine. There is no better background, it says, to a medical training than a university course in some other faculty, and it believes that the medical profession would benefit if more graduates in classics, history, languages or pure science entered it.

Although many readers of these two reports may prefer the proposals of the Goodenough Report for the selection of the medical student to those of the Committee of the Royal College of Physicians, all will agree with both committees that the masses of detail which now clutter up the medical curriculum should be resolutely pruned away. The emphasis, both Committees think, should be, during the early training in any event, on the teaching of principle and method. It will not be easy to select for removal the detail which the medical student will not require unless he should be able to show, at a later stage, that he is fitted to become, say, an anatomist, a surgeon, a pharmacologist or to enter some other field of work which requ res the acquisition of detailed knowledge. The Goodenough Committee rather emphasizes the difficulty of this task; but it does not shirk it. Such pruning could, its report suggests, reduce the duration of the medical training to four and a half years, and the report indicates the advantageous use of the time thus saved. This Committee further recommends that the curriculum should be constantly reviewed in the future by each medical school rather than by any body specifically appointed for this purpose. It will be necessary, however, not to exalt the teaching of principle and method so high that the value of factual knowledge is depreciated. too much. The Goodenough Committee emphasizes the teaching of observation and deduction of the meaning of facts observed and also the proper statement in words of these facts and deductions. But, although the student who crams facts can pass many examinations, whether they be medical or not, the training of the memory must not be neglected. Much of the practising doctor's efficiency depends upon a memory for detail, because it is done under conditions and in places which preclude consultation with others or reference to books. On the other hand, many of the existing text-books in common use should, it is widely agreed, be either scrapped altogether or entirely rewritten. The Goodenough Committee's plans would markedly reduce the doctor's need for books and works of reference : in place of them it would substitute constant living and personal contacts with specialists and others whose job it would be to keep the student and the practising doctor up to date and in touch with the latest methods and knowledge. There would be, for example, abundant and wisely planned postgraduate courses for practitioners and for any others who required them. The reorganization of the medical teaching centres and their better distribution about Great Britain would largely remove the geographical difficulties of any individual doctor who wished to keep his knowledge and practice up to date.

The training given to the student should provide him with an abiding eagerness to excel in current practice and to forge new tools for the service of his fellows. The Committee of the Royal College of Physicians emphasizes the convergence in medical education of the vocational education of the medical school and hospital and the academic training of the university. Sir Thomas Lewis (Lancet, 619 ; May 13, 1944 ; and 649, May 20, 1944) has discussed the same theme in some detail. The Goodenough Committee's proposal that every medical school should be an integral part of a university would give the medical student both these kinds of training. Clearly he must have both, even at the cost of the proposed disappearance of the Scottish extra-mural medical schools which have given much good training in the past.

The early clinical training should, the Committeo of the Royal College of Physicians believes, be an organized system of teaching correlated with the preclinical studies and with pathology, and it proposes an undergraduate clinical course, lasting three years, during which the teaching would be directed to principles and methods and the development of judgment rather than to the acquisition of factual knowledge. The Goodenough Committee formulates in detail a similar scheme, which is coupled with a scheme of pre-clinical teaching. The report urges the immediate initiation of this scheme. The whole scheme could not be adopted at once, because it 
involves far-reaching changes, some of which require some years for their completion. They are outlined on p. 322 of this issue. Those which concern the appointment of more whole-time clinical teachers and the betterment of their salaries and conditions of work need not be long delayed and are urgently required. It should not be very difficult, especially in these times of rapid large-scale reorganization, to establish quickly one or more of the medical teaching centres described by the Goodenough Committee; or to put into operation this Committee's plan for a Postgraduate Teaching Centre in Hammersmith; or to establish the experimental undergraduate medical school recommended for the University of Oxford. If these were started any faults in the schemes laid. down for them would be the more quickly deterted and remedied, and also more readily integrated with the national health service, which will itself require amendment as experience of its practice grows. Universal co-education of men and women in medicine, which the Goodenough Committee places in the forefront of its programme, should certainly be introduced immediately. It has, this Committee tells us, been the normal and successful practice for many years in all the medical schools outside London. It is time to end for good this injustice to our women. It would be of little use, however, to introduce this urgent reform unless steps were also taken to implement the Goodenough Report's further recommendations that all hospital appointments for qualified practitioners should be filled by open competition, and that the sex of the applicant should not be a bar to these appointments.

The mention of the qualified practitioner brings us to the important recommendations made by both the reports under consideration with regard to medical qualification. The Committee of the Royal College of Physicians would institute a final medical examination consisting of two parts. The first part would examine the candidate at the end of the three years clinical course which this Committee recommends, and this would be designed to test the candidate's knowledge of principles and methods rather than his knowledge of facts. On its results the candidate would receive his medical degree; but this would license him to practise medicine only in a hospital under supervision. He would still have to show that he is fitted to practise independently. To demonstrate this he would have to spend a compulsory year during which he would hold paid resident hospital appointments in general surgery, general medicine, obstetries and gynæcology, pediatrics and child health and in special studies. At the end of this year of hospital work the second part of the final examination would be taken. If the results of this showed that the candidate had sufficient practical and vocational ability, he would get his licence to practise independently. His further career would presumably be bound up with the national health scheme.

The Goodenough Report proposes a scheme conceived on the same general lines, but with only one examination; and many will think that it is the better scheme of the two. There has been, this report says, enthusiastic support for its recommendation that every medical student, after he has qualified but before he is admitted to the Medical Register and allowed to practi e independently, shall be re. quired to serve as a junior 'house' officer for a year at one or more approved hospitals. Before this War about half the students admitted to the Register did this, and during the War, regulations and conditions have raised this figure to more than 90 per cent. 'These 'house' appointments should be confined, the Goodenough Committee thinks, to departments of general medicine and surgery and each appointment should last at least six months. While they last the student should be enabled to obtain experience in special departments, but 'house' appointments in these special departments and in departments of obstetrics and gynæcology should be held after he has been admitted to the Medical Register. The Goodenough Committee does not propose a second examination at the end of this compulsory period of hospital appointments. It would be sufficient if the student submitted, when he applied for admission to the Medical Register, certificates to the effect that he had held the required appointments to the satisfaction of the authorities concerned.

The uninstrueted layman, who may be concerned very closely by these proposals, will no doubt heartily welcome them. They should, if they are combined with the Goodenough Committee's other recommendations, ensure for the public, in both health and sickness, the care of doctors who are doing their job because they like that kind of work and because they wish to serve their fellow men and women; and the work would be done by doctors of both sexes who would be as up to date as any planning can help to make them. If the public should get this kind of service-and it is to be hoped that the doctors themselves will be allowed to plan it, if only for the reason that they began to feel their way towards it long before any Government realized the necessity for any organized system of national health-the public itself has an obligation on its side. It must help the doctors. It must help to keep them as free as any other citizen to organize and do what they consider to be in the best interests of their patients. It must trust them when they say that their main purpose is to serve, as the best of them have served since the days of Hippocrates, their fellow men and women and to keep them in health, rather than to wait until they have to be treated for lack of health. We must all help also by allowing ourselves to be used, either as models of health or for the instruction of medical students in the signs and symptoms of disease. We must realize that we are members of a society inseparable from modern medicine and must therefore think as well as we can about the aspirations and difficulties of our doctors. We must think, too, of the betterment of the lot of women and children, which the recommendations of the two reports under consideration would inevitably bring about. These two reports, in fact, express, in a particular field, a major trend of modern thought which is exerting its practical effects all over the world. 